\title{
METODE PERKULIAHAN BAHASA ARAB YANG MENARIK DAN BERVARIASI MELALUI SISTEM PERKULIAHAN DARING
}

\author{
Zetty Arifah \\ STAI Yogyakarta \\ Email: zettyarifah6@gmail.com
}

\begin{abstract}
Almost all agencies in Indonesia apply the online method in 2020, learning is carried out optimally in WAG, Zoom, Google meet, Google Form and so on. This article aims to determine the form of Arabic lectures to improve students 'Arabic language skills at STAI Yogyakarta, which is marked by an increase in the skills of teachers in using technology and various Arabic learning strategies, student activeness in doing assignments given and students' Arabic language skills. by using media-based and communicative approaches and direct methods. Data were collected by observation, interviews, documentation and group discussion through WAG. The results of this research indicate that the lecturer implements various lecture activities creatively through WAG and Google Meet with different variations. Among them are lecture activities that prioritize the mastery of Mufrodat, namely strengthening the memorization of Arabic vocabulary and expressions in maharatul kalam. Maharotul Kalam mostly uses recorder activities, voice notes and explains pictures and real objects in the form of videos. For the mastery of mufrodat, besides video, it is also in the form of Arabic language games. Online activeness and presence increases after conducting various online courses.
\end{abstract}

Keywords: Online, WAG, Creative and Varied

\begin{abstract}
ABSTRAK
Hampir semua instansi di Indonesia menerapkan metode daring di tahun 2020 ini, pembelajaran terlaksana secara optimal baik dalam media WAG, Zoom, Google meet, Google Form dan sebagainya. Artikel ini bertujuan untuk mengetahui bentuk perkuliahan bahasa Arab untuk meningkatkan kemampuan bahasa Arab mahasiswa di STAI Yogyakarta yang ditandai dengan peningkatan ketrampilan guru menggunakan tekhnologi dan strategi pembelajaran Bahasa Arab yang bervariasi, keaktifan mahasiswa dalam mengerjakan tugas yang diberikan serta kemampuan bahasa Arab mahasiswa. dengan menggunakan berbasis media dan pendekatan komunikatif dan metode langsung. Data dikumpulkan dengan observasi, wawancara, dokumentasi dan group discussion melalui WAG. hasil dari riset ini menunjukkan bahwa dosen menerapkan berbagai aktifitas perkuliahan secara kreatif melalui WAG maupun Google Meet dengan variasi yang berbeda. Diantaranya aktivitas perkuliahanan yang mengedepankan penguasaan Mufrodat adalah penguatan hafalan kosakata dan ungkapan bahasa Arab dalam maharatul kalam. Untuk maharotul kalam lebih banyak menggunakan aktifitas recorder, voice note dan menjelaskan gambar maupun
\end{abstract}


benda-benda sebenarnya dalam bentuk video. Untuk penguasaan mufrodat selain video juga berbentuk game bahasa Arab. Keaktifan dan kehadiran online meningkat setelah melaksanakan perkuliahan daring yang bervariasi.

Kata Kunci: Daring, WAG, Kreatif dan Bervariasi

\section{PENDAHULUAN}

Keberhasilan perkuliahan sistem daring sangat dipengaruhi oleh dosen dalam memanfaatkan media tekhnologi. Mengubah pendekatan media tatap muka menjadi dalam jaringan melalui gambar, video, contoh model sebenarnya dan segala sesuatu yang dapat menjelaskan makna asing kepada mahasiswa. Kemampuan komunikasi aktif melatih mahasiswa menggunakan bahasa Arab secara spontanitas dan kreatif berani menggunakan bahasa Arab dalam mengungkapkan pikiran, perasaan dan kemauannya. ${ }^{1}$

Penggunaan metode langsung dimulai dari mendengarkan kata-kata, menirukannya secara lisan, dan komunikasi keseharian. Asas keberhasilan perkuliahan yaitu rasa mudah. Rasa mudah menimbukan semangat, dan semangat membawa kepada kerajinan dan kerajinan dapat menghasilkan keberhasilan dalam pembelajaran. Pembelajaran berbicara dapat berupa percakapan, chat, cerita dan pidato. Cerita melalui pengalaman yang didapatkan di lingkungan rumah, sekolah dan masyarakat. Mahasiswa diminta sering melihat dan mendengar percakapan melalui media elektronik sehingga mereka terbiasa dengan dialek penutur aslinya. Dosen memberi perhatian dengan menanyakan apa yang telah ditonton dan membahasnya melalui Group Discussion. Mufrodat disampaikan dengan gerakan maupun stiker, gambar, sampel, dan sebagainya.

Perkuliahan secara daring menuntut dosen untuk kreatif selain pembelajaran berbasis pada dosen mahasasiswa juga harus ikut aktif dan tidak hanya sekedar PR. PR yaitu tugas yang telah diketik oleh dosen dan mahasiswa tinggal menjawabnya melalui sebuah tulisan, hal itu menyebabkan mahasiswa hanya menguasai ketrampilan menulis. Hal itu bertentangan dengan sistem pembelajaran bahasa asing karena hakekat bahasa adalah

\footnotetext{
${ }^{1}$ Radliyah Zaenuddin dkk, Metode dan Strategi Alternatif Pembelajaran Bahasa Arab (Yogyakarta: Pustaka Rihlah Group, 2005), hlm. 34-36.
} 
berbicara. Dosen seharusnya terampil dalam menggunakan media dan alat peraga yang dapat meningkatkan ketrampilan berbicara bahasa Arab. Dosen menerapkan permainan bahasa dengan berbagai kecerdasan untuk mengkondisikan mahasiswa untuk terbiasa berbicara menggunakan bahasa Arab dengan berbagai sistem perkuliahan yang kreatif.

Perkuliahan bahasa Arab mahasiswa serigkali dengan komunikasi satu arah yaitu dosen menjelaskan materi selanjutnya mahasiswa diberi file tugas dalam bentuk word maupun google form. Terdapat juga dosen yang tidak menjelaskan langsung diberi file qiro'ah dan sejumlah pertanyaan tentang isi qiro'ah tersebut. Rata-rata perkuliahan daring itu sangat mandiri karena teks bacaan maupun mufrodat bisa diartikan melalui google translate. Walaupun memudahkan mahasiswa dalam menjawab pertanyaan tetapi mahasiswa kurang mengetahui apakah bahasa yang digunakan itu Fusha atau 'Amiyah.

\section{METODE PENELITIAN}

Metode penelitian yang dipergunakan dalam penelitian ini adalah metode kualitatif dengan pendekatan library research. Peneliti menggunakan literatur (kepustakaan) baik berupa buku, catatan, dokumen, jurnal dan laporan hasil penelitian. Penelitian juga dilakukan dengan melakukan pengamatan perkuliahan daring suatu kampus dan pengalaman peneliti sebagai dosen Bahasa Arab. Dengan menggunakan pendekatan kualitatif peneliti dapat memahami, mengamati, mencermati dan menganalisis serta melakukan penelaahan lebih akurat berkenaan dengan peran dosen dalam pembelajaran Bahasa Arab secara daring. Peneliti akan mengkaji dan meneliti secara objektif tentang secara objektif tentang bagaimana keefektifan perkuliahan daring dalam meningkatkan kemampuan bahasa Arab mahasiswa. 


\section{HASIL DAN PEMBAHASAN}

Riset ini dilaksanakan dengan pendekatan langsung, komunikatif dan media. Strategi yang digunakan rata-rata dengan pendekatan berbasis guru yaitu video call dalam google meet serta komunikasi satu arah yaitu pemberian tugas dan kebanyakan melatih maharatul Kitabah mahasiswa. Penelitian ini membahas sistem perkuliahan bahasa Arab mahasiswa melalui daring. Oleh karena itu berkaitan dengan kemampuan dosen dalam menggunakan tekhnologi. Terdapat beberapa dosen yang gagap dalam menggunakan tekhnologi sehingga Zoom, google meet dan media presentasi sangatlah terbatas. Mayoritas guru maupun dosen menggunakan aplikasi kesehariaannya untuk memberikan materi yaitu WAG dengan bentuk yang berbeda.

Kegiatan mengajar Work from Home rata-rata guru memberikan tugas siswa berupa mengerjakan latihan di buku modul, mengerjakan tugas tertulis, hafalan mufrodat, mendengarkan musik lalu mempraktekkannya dengan membuat video lalu dikirimkan ke pengajarnya. ${ }^{2}$

Meningkatnya kemalasan mahasiswa dalam mengikuti perkuliahan karena kelas online tidak ada ruang konferensi virtual, tidak ada interaksi dengan dosen dan minimalnya materi yang diberikan oleh dosen serta minimalnya bahkan meniadakan diskusi dan presentasi yang layak. Perkuliahan daring banyak ditemukan kurang efektif karena sama saja dengan pertemuan tatap muka yang jadi tulisan. Mahasiswa hanya diberikan sebuah materi yang diketik dan beberapa soal sehingga sama saja belajar secara otodidak dengan google.

Dosen dituntut untuk meningkatkan kemampuannya dalam menggunakan tekhnologi dan aplikasi. Fasilitas yang digunakan dosen seharusnya tidak sebatas smartphone akan tetapi juga laptop, trypod, headset dan file presentasi dan animasi agar menggugah semangat mahasiswa. Seharusnya dalam perkuliahan dosen dan mahasiswa bisa aktif dengan setiap pertemuan menggunakan aplikasi ataupun perkuliahan yang bervariasi.

\footnotetext{
${ }^{2}$ Al-Mudarris: journal of education, Vol. 3. No. 1 April 2020, ISSN: 2620-5831, ISSN; 2620-4355 (online)
} 
Perkuliahan daring terutama mata kuliah bahasa Arab dalam media WAG Pertemuan pertama menggunakan dengan sistem percakapan antara mahasiswa dengan guru menggunakan arabic chat. Mahasiswa dapat mencarinya dalam google translate dan dikoreksi oleh dosen bahasa mana yang lebih sering digunakan. Respon mahasiswa yang paling banyak dan aktif akan menjadi penilaian tersendiri. Untuk siswa yang kurang merespon dan tidak merespon sama sekali diberikan tugas yang lebih berat.

Pertemuan kedua dengan mengirimkan sebuah vidio percakapan bahasa arab dari yutube untuk ditirukan mahasiswa dan memahami kosakatanya lalu dibahas artinya dalam WA grup. Mahasiswa diberi tugas mengarang dan bercakap-cakap tentang ungkapan sehari hari dalam bentuk chat dari dosen.

Pertemuan ketiga dosen memberikan sebuah video karya dosen itu sendiri dalam bentuk berbicara dengan bahasa arab misalnya tentang kegiatan sehari-hari. Mahasiswa mengungkapkan kembali dengan isi yang berbeda dalam voice note ataupun recorder. Mahasiswa dan dosen mengirimkan video serta penjelasan tertulis dan suara dengan melihat benda dan suasana sebenarnya lalu menceritakan atau mengungkapkannya dalam bahasa arab melalui alat peraga atau media sesungguhnya.

Pertemuan keempat dosen membagikan link-link yang dianggapnya mudah dalam belajar bahasa arab serta tidak lupa chat dengan mahasiswa menggunakan bahasa Arab agar mahasiswa terlatih berbicara bahasa Arab walaupun kadang disisipi dengan bahasa pegon atau indonesia Arab. Mahasiswa di drill dengan berbicara bahasa Arab walaupun kadang disambi membaca teks. Mahasiswa berpidato dan dengan video maupun video call.

Dosen memanfaatkan tekhnologi presentasi zoom, penugasan via google classroom, quiz, google drive dan lain-lain. Dosen memberikan aplikasi game untuk melatih kosakata mahasiswa secara menyenangkan. Kebanyakan pengajar bahasa arab membuat materi pembelajaran berupa percakapan atau bacaan yang sudah ada terjemahannya menggunakan program $m s$ word, power point atau mengambil materi dari youtube. Materi tersebut dikirim ke siswa melalui WA grup per kelas. Siswa memahami 
materi, lalu mengerjakan tugas. Untuk menerjemahkan boleh menggunakan kamus maupun google translate, bila ada kesulitan langsung japri. ${ }^{3}$

Setelah dosen menjelaskan materi mahasiswa diberikan quiz dan challange mufrodat, seperti tiktok. Menyanyikan mufrodat ataupun membuat karya percakapan dengan madlipz. Dengan membuat dan menonton karya madlipz seperti karya @muslikhin_m mahasiswa akan terhibur dan semangat belajar bahasa Arab. Berlomba berkarya dan setoran rekaman.

Guru atau dosen memberikan tugas berupa mengerjakan soal latihan, mengerjakan tugas tertulis, tes online praktek, hafalan mufrodat, mendengarkan musik dan membuat video. Dosen membuat soal dalam google form yang diambil dari modul yang telah diberikan dosen. Adapun metode pembelajaran metode ceramah, diskusi, demonstrasi, pembelajaran resitasi, eksperimen, karta wisata, latihan, perancangan dan debat tetapi berubah sejak pandemi mahasiswa dituntut untuk belajar memahami sendiri. Sehingga mahasiswa belum tentu memahami materi. Meskipun kegiatan pembelajaran bisa melalui Wag video call tetapi tidak bisa berjalan semulus yang dibayangkan.

Mahasiswa yang aktif lebih suka konferensi virtual melalui google meet dan semacamnya daripada menggunakan Wag. Menggunakan Wag yang bervariasi misalnya mengirimkan powerpoint maupun file gambar yang dijelaskan dosen berbahasa Arab dengan media gambar, misalnya pemandangan pasar, sekolah, pantai, supermarket dan sebagainya yang mengandung banyak mufrodat. Mahasiswa membuat dokumentasi yang dijelaskan dengan bahasa Arab berdasar tema yang diberikan dosen. Jika dosen mempunyai banyak job mahasiswa bisa diajak berkompetisi lomba menulis karya dan membuat media berbahasa Arab. Dosen membuat simbolsimbol dan emoticon untuk dijadikan media perkuliahan maharatul kalam.

Mahasiswa diajari membuat pohon keluarga maupun bentuk yang bermacam-macam dari peta konsep agar mudah diingat. Mahasiswa diberi file gambar ular tangga dan mahasiswa diukur melalui banyaknya yang dijawab dan waktu finishnya. Sebenarnya mudah saja belajar online bahasa

\footnotetext{
${ }^{3}$ https://bernasnews.com
} 
Arab yaitu madlipz dan game bahasa Arab banyak di play store apalagi game yang diciptakan oleh dosen itu sendiri. Mahasiswa membuat iklan produk makanan atau minuman berbahasa arab. Dosen memberikan sejumlah gambar dalam $m s$ word diprint lalu dipotong-potong dan digunakan dalam response belajar mufrodat dalam video call maupun google clasroom. Yang terpenting disini belajar bahasa arab dengan game, video, gambar maupun poster.

Dari kontribusi dosen yang inisiatif membuat materi baik dalam naskah pdf, PTT bahkan ada yang pakai video itu sangat membantu. Sayangnya tidak semua dosen kompeten dan peduli terhadap keadaan kelas maupun kemampuan mahasiswa. Terdapat beberapa dosen yang hanya memberi tugas dan dikumpulkan tanpa memberikan penjelasan apapun dan koreksi dari karya tulis mahasiswa tersebut karena menganggap smartphone mereka bisa memunculkan semua ilmu. Pembelajaran sistem daring membuat sebagian mahasiswa mengambil jalan yang seenaknya sendiri yang penting presensi tanpa mengambil ilmu yang ada di dalamnya. Penjadwalan presentasi juga kurang efektif karena tidak semua menyimak dan seringkali belum siap untuk presentasi. Seringkali kehadiran mahasiswa kurang dari $50 \%$.

Beberapa alasan mereka tidak mengikuti perkuliahan online karena ketinggalan materi, kerja, bantuin kerja dirumah, waktunya pas gantiin orang tuanya jaga warung dan sebagainya sehingga lupa waktu. Waktu daring bisa dianggap nanggung bagi mereka yang mempunyai tugas lain yang belum terselesaikan. Cenderung malu untuk menampakkan dirinya di jam-jam akhir meeting. Mahasiswa yang berdomisili di pondok juga mengatakan bahwa situasi pondok tidak menentu jadi jadwal daring baik via zoom atau yang lainnya bertabrakan dengan jadwal yang ada di pondok. Kebanyakan mahasiswa pondok lebih mengutamakan kegiatan yang diselenggarakan pondoknya.

Sistem daring via Zoom atau Google meeting menyebabkan mahasiswa kesulitan bagi mereka yang mempunyai smatphone yang Ramnya kecil karena memorinya penuh dan mempertahankan aplikasi-aplikasi yang dikiranya lebih penting. Memang daring tidak efektif bagi mereka yang 
kurang disipin membagi waktu, walaupun dirumah tapi pekerjaan membantu keluarganya itu lebih banyak karena bagi mereka dirumah itu libur.

Memang kemampuan mahasiswa lebih meningkat pada pembelajaran tatap muka karena mereka bisa aktif dari berbagai faktor, bisa faktor berbicara, faktor yang lain karena mahasiswa berbeda-beda macam kecerdasannya. Tatap muka bisa bermain-main dengan media pembelajaran yang banyak dan bisa mendebat dosennya secara maksimal tanpa ada kendala jaringan dan lainnya. Perkuliahan bahasa juga lebih efektif pada saat tatap muka karena percakapan lebih mudah dilakukan. Tatap muka lebih mudah dilakukan karena dosen tidak perlu menyiapkan media perkuliahan. Referensi hardcopy lebih dipahami daripada softcopy.

Solusi terbaik bagi perkuliahan bahasa Arab sistem daring yaitu dengan membuat animasi video percakapan, game, video benda dan tempat sebenarnya, serta metode yang berbeda-beda setiap kali pertemuan. Macammacam strategi dan metode yang bisa digunakan pada sistem daring yaitu:

1. Ta'bir Mushawwar

Ta'bir Mushawwar yaitu menjelaskan gambar atau bercerita dari gambar. ${ }^{4}$ Gambar bisa buat sendiri atau dari gambar yang ditemukan di media. File gambar bisa dikirimkan ke peserta didik.

2. Ghina'

Ghina' yaitu bernyanyi, baik itu lagu arab asli atau lagu daerah maupun pop yang diarabkan. Dosen memberikan contoh video lagu dan lebih baik karya dosen sendiri agar mereka lebih bersemangat.

3. Khitobah dan membaca berita

Sebaiknya pidato dan membaca cerita mahasiswa juga mengirimkan file terjemahannya agar mufrodat nya bisa dikoreksi. Dalam pidato tidak dibatasi oleh banyaknya paragraf agar mahasiswa menguasai tidak hanya menghafalkan

4. Qishoh

\footnotetext{
${ }^{4}$ Radliyah Zaenuddin dkk, Metode dan Strategi Alternatif Pembelajaran Bahasa Arab (Yogyakarta: Pustaka Rihlah Group, 2005), hlm. 68
} 
Dosen bercerita dengan pelan dan jelas sementara mahasiswa mendengarkan untuk mengisi sejumlah pertanyaan yang berkaitan dengan cerita. pertanyaan sebaiknya tidak lebih dari 10 nomor agar mahasiswa menikmati alur belajar bahasa asing dengan nyaman.

5. Mengharakati kalimat

Dengan mengharakati kata atau mengi'rob mahasiswa akan tambah penasaran karena harakat bisa berubah-ubah dalam beberapa posisi.

6. Tartib al-Nash

Mengurutkan kalimat atau cerita acak. Dosen menjelaskan arti dari sebuah cerita arab lalu mahasiswa mengurutkan alur cerita yang benar.

7. Game

Dosen mencari game bahasa Arab di Play Store yang bagus, menarik dan berbobot untuk dimainkan. Dosen dan mahasiswa mengirimkan hasil akhir berupa score game.

8. Model

Dosen dan mahasiswa mencari model di tempat terdekat untuk menjelaskan model maupun tempat tersebut, misal rumah terdiri dari berbagai ruangan dan benda serta fungsinya.

9. Al Kalimat al-Musalsalah

Al Kalimat al-Musalsalah ialah Meneruskan kata baik isim fi'il. Dosen menyebutkan sebuah kata dan mahasiswa meneruskan kata lainnya dengan melihat huruf akhirnya. Metode ini bisa digunakan dengan chat.

10. Emoticon Stiker

Dosen mencari sebanyak-banyaknya stiker untuk pembelajaran mufrodat agar lebih menarik dan memperbanyak kosakata.

11. Membuat Museum

Suruh murid-murid memilih sesuatu dari alam (nyata atau model) yang mereka ingin pajang dimuseum misalnya kerang, dedaunan, biji-bijian, tanaman, kupu-kupu dan sebagainya. Dengan sebuah museum atau koleksi mereka akan menjelaskannya dengan bahasa asing atau bahasa arab. ${ }^{5}$

\footnotetext{
${ }^{5}$ Barbara Allman dan Sara Freeman, menjadi Guru Kreatif agar dicintai murid sampai mati. (Yogyakarta: Golden Books, 2010) 173.
} 
12. Mencari atau Menjelaskan Perbedaan Gambar ${ }^{6}$

Dosen mencari atau membuat dua gambar yang mirip tapi ada berbagai perbedaan yang sulit ditebak. Misalnya gambar pemandangan di hutan terdapat sejumlah kera perbedaannya dua telinga kera kecil lebih besar, tampak tangan kiri kera besar, di tangan monyet besar ada pisang, roda mobil lebih kecil, gunung sedikit lebih pendek, kepala laki-laki tanpa ikat kepala, bagian depan mobil tidak ada lampu sorot.

\section{SIMPULAN}

Perkuliahan sistem daring yang menarik dan efektif melalui gambar, video, contoh model sebenarnya dan segala sesuatu yang dapat menjelaskan makna asing kepada mahasiswa. Pembelajaran berbicara dapat berupa percakapan, chat, cerita dan pidato. Cerita melalui pengalaman yang didapatkan di lingkungan rumah, sekolah dan masyarakat. Mufrodat disampaikan dengan gerakan maupun stiker, gambar, sampel, dan sebagainya. Perkuliahan secara daring menuntut dosen untuk kreatif yaitu dengan membuat animasi video percakapan, game, video benda dan tempat sebenarnya, serta metode yang berbeda-beda setiap kali pertemuan. Dosen juga harus kreatif membuat vidio yang menarik seperti madlipz dan mencari bahan yang menarik di yutube. Jika menggunakan Google Meet maka dengan power point yang menarik dan medianya yang lengkap. Mengajar Bahasa Arab sebagai bahasa asing harus pelanpelan dengan praktek berbicara tidak memperbanyak teori.

\footnotetext{
${ }^{6}$ Nasif Mustofa Abdul Azis, Al'ab Al lughowiyah fi Ta'limi Lughoh Al-Ajnabiyah (Riyadh: Fakultas Ilmu Bahasa dan Budaya, 1401 H), 135.
} 


\section{DAFTAR PUSTAKA}

Abdul Azis, Nasif Mustofa, Al'ab Al lughowiyah fi Ta'limi Lughoh Al-Ajnabiyah. Riyadh: Fakultas Ilmu Bahasa dan Budaya, $1401 \mathrm{H}$.

Allman, Barbara dan Sara Freeman, menjadi Guru Kreatif agar dicintai murid sampai mati. Yogyakarta: Golden Books, 2010.

Al-Mudarris: journal of education, Vol. 3. No. 1 April 2020, ISSN: 2620-5831, ISSN; 2620-4355 (online)

bernasnews.com

Zaenuddin, Radliyah dkk, Metode dan Strategi Alternatif Pembelajaran Bahasa Arab. Yogyakarta: Pustaka Rihlah Group, 2005. 